\title{
Changes in the Parameters of Systemic Hemodynamics and Perfusion during Laparoscopic Cholecystectomy in Patients with Acute Cholecystitis and Possible Correction Methods
}

\author{
Alexander N. Golomidov, MD; Serhiy H. Hryvenko, MD, PhD, ScD*; \\ Evelina R. Kondratiuk, MD, PhD; Yuriy V. Artemov, MD, PhD; \\ Alexander V. Kosenko, MD, PhD; Idris V. Dzhemilov \\ Medical Academy named after S.I. Georgievsky of Vernadsky CFU \\ Simferopol, Crimea
}

\begin{abstract}
This article presents a clinical and laboratory assessment of the effectiveness of the author's method for pharmacological correction of hypoxic changes at acute pneumoperitoneum in patients with acute calculous cholecystitis (ACC) during laparoscopic cholecystectomy (LCE) (Patent of Ukraine No. 119602). The application of the developed technique allows leveling of ischemic and reperfusion changes that occur during LCE in ACC patients by protectively affecting blood lactate level, statistically significantly reducing it after desufflation. The proposed method reduces the number of cardiovascular complications provoked by ischemic disorders on the background of pneumoperitoneum by 3.79 times. (International Journal of Biomedicine. 2020;10(2):133-137.)
\end{abstract}

Key Words: acute calculous cholecystitis $\bullet$ laparoscopic cholecystectomy $\bullet$ systemic hemodynamics $\bullet$ perfusion $\bullet$ hypoxia

\section{Abbreviations}

ACC, acute calculous cholecystitis; AR, anesthetic risk; BLL, blood lactate level; CVC, cardiovascular complication; LCE, laparoscopic cholecystectomy; HR, heart rate; SBP, systolic blood pressure; DBP, diastolic blood pressure; LDH, lactate dehydrogenase; MBP, mean blood pressure; PP, pneumoperitoneum

\section{Introduction}

The most significant, revolutionary surgical event of recent decades was the rapid development and introduction into wide clinical practice of endoscopic surgical methods that radically changed the face of modern surgery. Of all sections of endoscopic surgery, laparoscopy is the most developed. Huge opportunities have opened up for the use of endo-surgical technologies, not only in planned, but also in emergency abdominal surgery. ${ }^{(1-5)}$

*Corresponding author: Serhiy H. Hryvenko, MD, PhD, ScD. Medical Academy named after S.I. Georgievsky of Vernadsky CFU, Simferopol, Crimea.E-mail: hryva@mail.ru
In the structure of urgent surgical diseases of the abdominal cavity organs, acute calculous cholecystitis (ACC) is one of the most common nosologies. The incidence of ACC in the Russian Federation is second only to acute appendicitis and amounts to $1-1.5$ cases per 1,000 adults. ${ }^{(6)}$ A modern method for ACC treatment is laparoscopic cholecystectomy (LCE). ${ }^{(7-11)}$ One of the characteristic features of laparoscopic operations is the need to create pneumoperitoneum (PP), which provides optimal visualization of anatomical structures. Most often, carbon dioxide is used as the insufflated gas. A combination of prolonged abdominal pressure and effects of the intraabdominal presence of carbon dioxide has a complex effect on the patient's body. Pathophysiological shifts arising during the pneumoperitoneum creation, primarily from the cardiovascular and respiratory systems, increase the risk of the operation. ${ }^{(12)}$ In 
this regard, it is relevant to search for ways to reduce the negative impact of pneumoperitoneum on bodily functions when using laparoscopic surgery. ${ }^{(13)}$ Since the leading pathogenetic link in the disorders accompanying intense pneumoperitoneum is hypoxia, its pharmacological correction is of particular interest.

The aim of this study was to increase the efficiency of surgical treatment of patients with ACC during LEC on the basis of the development and implementation in clinical practice of a new pathogenetically substantiated method of pharmacological correction of hypoxic changes in cases of intense pneumoperitoneum.

\section{Materials and Methods}

The study was based on the analysis of clinical and laboratory monitoring of the results of surgical treatment of 102 patients with a verified diagnosis of ACC who underwent LCE in Surgical Department No.1 of Simferopol Clinical Emergency Hospital No. 6 in the period from 2017 to 2019.

The study was carried out in compliance with Ethical Principles for Medical Research Involving Human Subjects, Adopted by the 18th WMA General Assembly, Helsinki, Finland, June 1964, and amended by the 59th WMA General Assembly, Seoul, Republic of Korea, October 2008. Written informed consent was obtained from all patients before inclusion in the study.

The criteria for inclusion of patients in the study were these: over 18 years of age and informed consent of the patient. Exclusion criteria: body mass index over $38 \mathrm{~kg} / \mathrm{m}^{2}$, decompensated organ failure, and conversion to laparotomy due to complications or technical difficulties that developed or were found during the laparoscopic procedure.

All patients included in the study were admitted in order of urgency. In accordance with the design of the work, on the basis of simple randomization, depending on the method of preoperative preparation, intraoperative support and management of the postoperative period, two groups of patients were formed and structured. The two groups were similar with regard to age, gender, and nosological characteristics. In the comparison group $(\mathrm{CC}, \mathrm{n}=58)$, patients underwent traditional preoperative preparation, intraoperative support and postoperative management. In the main group (MG, $\mathrm{n}=44$ ), in addition to the stages of preoperative preparation, intraoperative support and postoperative management, the proposed author's method for the prevention and treatment of hypoxic changes, a succinate-containing drug, meglumine sodium succinate (Fig.1) (brand name "Reamberin"), was used. ${ }^{(14)}$

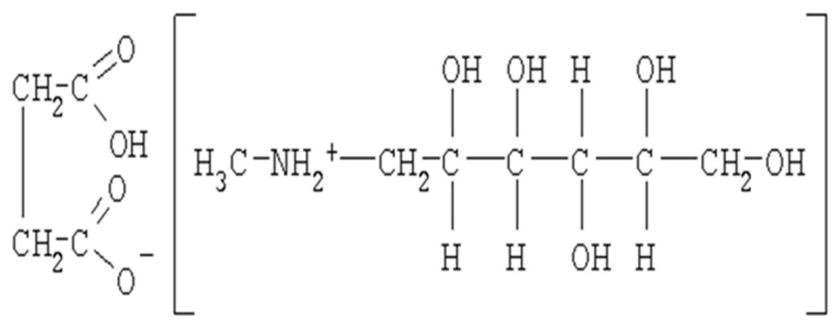

Fig.1. The chemical formula of meglumine sodium succinate
Meglumine sodium succinate in the form of a solution for infusion is included in the list of vital and most important drugs for medical use in the Russian Federation.

The average age of the patients included in the study was $56.55 \pm 1.24$ years. The largest group comprised elderly patients, who made up more than half of all those studied $-51.96 \%$. The average age of the patients in MG and CG was $58.39 \pm 1.98$ years and $55.16 \pm 1.78$ years, respectively. Women were prevalent in the gender structure of patients in the study groups (34/77.3\% in MG and 45/77.6\% in CG).

In both groups, patients with destructive forms of ACC predominated $(41 / 88.6 \%$ in $\mathrm{MG}$ and $42 / 72.4 \%$ in CG). Patients with acute phlegmonous cholecystitis predominated in the structure of destructive forms of ACC in both groups (35/81.8\% in MG and 38/65.5\% in CG). Accordingly, patients with a catarrhal form of ACC in MG amounted to $5 / 11.4 \%$ and $16 / 27.69 \%$ in CG.

The existing, concomitant somatic pathology increases the risks when creating PP, operational and anesthetic risk, and creates the prerequisites for postoperative complications and prolongation of the patient's hospital stay. Concomitant chronic diseases in patients of both groups were in the stage of compensation and did not constitute contraindications for surgery. None of the identified concomitant diseases at the time of treatment and at the treatment stages had a pronounced manifestation and did not significantly affect the results of the presented study. Among the concomitant diseases, cardiovascular pathology was the leading one, which is explained by the prevalence of elderly patients in the age structure of both groups. Among all cardiovascular diseases, arterial hypertension prevailed. The number of patients with this concomitant pathology in MG and CG was $16 / 36.4 \%$ and $23 / 39.7 \%$, respectively. Patients in both groups were compensated for hemodynamic parameters before surgery.

The average Charlson comorbidity index in $\mathrm{MG}$ was $3.00 \pm 0.26(\mathrm{Me}=3.00)$, and 2.59 $\pm 0.21(\mathrm{Me}=3.00)$ in CG. Before surgery, AR was assessed in patients of both clinical groups, according to the American Society of Anesthesiologists scale. The most numerous patients in both clinical groups were patients with AR II $(29 / 65.9 \%$ in MG and $39 / 67.2 \%$ in CG). AR I was found in $11 / 18.97 \%$ of patients in CG and in $5 / 11.4 \%$ of patients in MG; AR III in $7 / 12.1 \%$ and $10 / 22.7 \%$, respectively.

Patients in both groups underwent a standard 4-port LCE using a clipper under endotracheal anesthesia and mechanical ventilation. The working space was created by carboxyperitoneum at a pressure of $10-12 \mathrm{mmHg}$. The average duration of surgery was $84.20 \pm 5.22$ minutes $(\mathrm{Me}=80.00$ minutes) in $\mathrm{MG}$ and $76.88 \pm 5.16$ minutes $(\mathrm{Me}=65.00$ minutes $)$ in $\mathrm{CG}$.

In all patients, using the MINDRAY IPM-10 monitor (China), the most informative hemodynamic parameters were assessed before surgery, 30 minutes after the start of surgery, and after desufflation. The state of blood circulation was also assessed by MBP defined by the formula: $\mathrm{MBP}=\mathrm{DBP}+(\mathrm{SBP}-$ DBP)/2. MBP corresponds to constant pressure in the aorta, which provides a sufficient hemodynamic effect for adequate organ perfusion. It is believed that $\mathrm{MBP}>60 \mathrm{mmHg}$ is 
sufficient for the functioning of organs. Normally, the MBP indicators range from $70 \mathrm{mmHg}$ to $110 \mathrm{mmHg}$.

$\mathrm{SpO}_{2}$, acid-base equilibrium $(\mathrm{pH})$ and lactate levels in venous blood we estimated before surgery, 30 minutes after the start of LCE and after desufflation using a GEM Premier 3500 automatic analyzer of blood gases, electrolytes and metabolites (Instrumentation Laboratory, USA). The content of LDH in the venous blood was determined at similar time periods using the UV kinetic test in units per liter (Norm 0.0 $247.0 \mathrm{U} / \mathrm{L})$.

The statistical analysis was performed using the statistical software Microsoft Excel 2010. Student's unpaired and paired t-tests were used to compare average values for data with normal distribution. A probability value of $\mathrm{P}<0.05$ was considered statistically significant.

\section{Results}

The parameters of systemic hemodynamics at the stages of surgical treatment in CG are presented in Table 1. Thirty minutes after the creation of pneumoperitoneum with a pressure of 10-12 mmHg, a significant decrease in all indicators was noted. Thus, HR, SBP, DBP and MBP decreased by $2.72 \%$, $16.11 \%, 12.53 \%$, and $14.74 \%$, respectively. After desufflation, the inertial decrease in the levels of all the studied parameters continued. Thus, at this stage, compared with the preoperative period, the decrease in HR, SBP, DBP and MBP was 5.1\%, $16.2 \%, 13.4 \%$, and $15.1 \%$, respectively.

\section{Table 1.}

Parameters of systemic hemodynamics at the stages of surgical treatment in the comparison group

\begin{tabular}{|c|c|c|c|c|}
\hline \multicolumn{1}{|c|}{ Stages } & $\begin{array}{c}\mathrm{HR} \\
(\mathrm{bpm})\end{array}$ & $\begin{array}{c}\text { SBP } \\
(\mathrm{mmHg})\end{array}$ & $\begin{array}{c}\mathrm{DBP} \\
(\mathrm{mmHg})\end{array}$ & $\begin{array}{c}\mathrm{MBP} \\
(\mathrm{mmHg})\end{array}$ \\
\hline Before surgery & $75.38 \pm 1.53$ & $142.47 \pm 2.26$ & $89.09 \pm 1.40$ & $115.78 \pm 1.74$ \\
\hline $\begin{array}{l}30 \text { minutes after } \\
\text { PP creation }\end{array}$ & $73.33 \pm 1.30$ & $119.52 \pm 1.94$ & $77.93 \pm 1.49$ & $98.72 \pm 1.62$ \\
\hline $\begin{array}{l}\text { After } \\
\text { desufflation }\end{array}$ & $71.51 \pm 1.24$ & $119.36 \pm 1.55$ & $77.19 \pm 1.33$ & $98.28 \pm 1.35$ \\
\hline$P$ & $<0.05$ & $<0.05$ & $<0.05$ & $<0.05$ \\
\hline
\end{tabular}

The parameters of systemic hemodynamics at the stages of surgical treatment in MG are presented in Table 2. Thirty minutes after the creation of pneumoperitoneum with a pressure of $10-12 \mathrm{mmHg}$, a significant decrease in all indicators was noted. Thus, HR, SBP, DBP and MBP decreased by $6.05 \%, 22.39 \%, 18.38 \%$, and $20.18 \%$, respectively. After desufflation, the inertial decrease in the level of HR continued (by $6.75 \%$ compared with the preoperative period). In contrast to $\mathrm{CG}$, the remaining indicators of systemic hemodynamics showed steady growth, although they did not reach the initial preoperative values by this time period. Thus, at this stage, compared with the preoperative period, the decrease in SBP, DBP and MBP was $17.8 \%, 16.8 \%$, and $17.4 \%$, respectively.

Table 2.

Parameters of systemic hemodynamics at the stages of surgical treatment in the main group

\begin{tabular}{|l|c|c|c|c|}
\hline \multicolumn{1}{|c|}{ Stages } & $\begin{array}{c}\mathrm{HR} \\
(\mathrm{bpm})\end{array}$ & $\begin{array}{c}\mathrm{SBP} \\
(\mathrm{mmHg})\end{array}$ & $\begin{array}{c}\mathrm{DBP} \\
(\mathrm{mmHg})\end{array}$ & $\begin{array}{c}\mathrm{MBP} \\
(\mathrm{mmHg})\end{array}$ \\
\hline Before surgery & $79.41 \pm 1.70$ & $146.61 \pm 2.45$ & $93.66 \pm 1.51$ & $120.14 \pm 1.84$ \\
\hline $\begin{array}{l}30 \text { minutes after } \\
\text { PP creation }\end{array}$ & $74.61 \pm 1.37$ & $115.34 \pm 2.08$ & $76.45 \pm 1.97$ & $95.90 \pm 1.93$ \\
\hline $\begin{array}{l}\text { After } \\
\text { desufflation }\end{array}$ & $74.05 \pm 1.21$ & $120.52 \pm 1.91$ & $77.93 \pm 1.05$ & $99.23 \pm 1.34$ \\
\hline$P$ & $<0.05$ & $<0.05$ & $<0.05$ & $<0.05$ \\
\hline
\end{tabular}

Analysis of $\mathrm{SpO}_{2}$ in patients of CG showed a moderate decrease from $97.88 \pm 0.76 \%$ to $96.25 \pm 1.87 \%$ when creating intense pneumoperitoneum (Table 3). After carbon dioxide desufflation, the $\mathrm{SpO}_{2}$ rate was restored and almost corresponded to the average level before the operation, which testified to the temporary negative effect of pneumoperitoneum. The average blood $\mathrm{pH}$ during carbon dioxide insufflation was normal and amounted to $7.391 \pm 0.002$; during the operation, it slightly decreased to $7.386 \pm 0.012$, which is explained by the development of moderate respiratory acidosis due to an increase in intra-abdominal pressure (Table 3). The shift of acidbase balance towards acidosis correlated with hemodynamic changes. After elimination of pneumoperitoneum, the average blood $\mathrm{pH}$ was $7.395 \pm 0.002$, which indicated stabilization of the acid-base balance due to adequate ventilation.

Table 3.

Parameters of $\mathrm{SpO}_{2}$ blood $\mathrm{pH}$ and biomarkers of tissue hypoxia at the stages of surgical treatment in the comparison group

\begin{tabular}{|l|c|c|c|c|}
\hline \multicolumn{1}{|c|}{ Stages } & $\mathrm{SpO}_{2}, \%$ & $\mathrm{pH}$ & $\begin{array}{c}\mathrm{BLL}, \\
\mathrm{mmol} / \mathrm{L}\end{array}$ & $\begin{array}{c}\mathrm{LDH}, \\
\mathrm{U} / \mathrm{L}\end{array}$ \\
\hline Before surgery & $97.88 \pm 0.76$ & $7.391 \pm 0.002$ & $1.27 \pm 0.03$ & $179.55 \pm 3.55$ \\
\hline $\begin{array}{l}30 \text { minutes after } \\
\text { PP } \\
\text { creation }\end{array}$ & $96.25 \pm 1.87$ & $7.386 \pm 0.012$ & $1.77 \pm 0.06$ & $174.55 \pm 3.75$ \\
\hline $\begin{array}{l}\text { After } \\
\text { desufflation }\end{array}$ & $98.87 \pm 0.23$ & $7.395 \pm 0.002$ & $1.96 \pm 0.04$ & $161.25 \pm 3.83$ \\
\hline \multicolumn{1}{|c|}{$P$} & $>0.05$ & $>0.05$ & $<0.05$ & $<0.05$ \\
\hline
\end{tabular}

Thus, in the patients of CG, hemodynamic and perfusion changes were noted, which were also reflected in 
the shifts of the acid-base state in response to stress due to the operation and the creation of pneumoperitoneum. At the same time, when analyzing blood biomarkers of tissue hypoxia (Table 3), significant changes were found when creating pneumoperitoneum. Despite the fact that blood lactate level in all measured time intervals corresponded to the physiological norm, a significant increase was noted after performing laparoscopic cholecystectomy, relative to the initial data $(1.96 \pm 0.04 \mathrm{mmol} / \mathrm{L}$ versus $1.27 \pm 0.03 \mathrm{mmol} / \mathrm{L})$. Fluctuations in lactate dehydrogenase levels at the same time had the opposite character. There was a moderate decrease in the lactate dehydrogenase level after performing laparoscopic cholecystectomy, relative to the initial data $(161.25 \pm 3.83 \mathrm{U} / \mathrm{L}$ versus $179.55 \pm 3.55 \mathrm{U} / \mathrm{L}$ ).

Analysis of $\mathrm{SpO}_{2}$ in patients of MG (Table 4) did not reveal statistically significant changes during gas insufflation. Thirty minutes after the start of surgery, $\mathrm{SpO}_{2}$ slightly decreased from $97.63 \pm 0.58 \%$ to $96.14 \pm 1.21 \%$. After gas desufflation, the $\mathrm{SpO}_{2}$ level recovered and remained within the physiological norm. The average blood $\mathrm{pH}$ during carbon dioxide insufflation was normal and amounted to $7.39 \pm 0.002$ before the operation; during the operation it remained practically unchanged (7.4 \pm 0.001$)$; therefore, pronounced respiratory acidosis with intense pneumoperitoneum was not observed. After desufflation, the average blood $\mathrm{pH}$ remained at the same level $(7.4 \pm 0.001)$, which indicated the complete stabilization of the acid-base balance due to the maintenance of adequate ventilation.

\section{Table 4.}

Parameters of $\mathrm{SpO}_{2}$, blood $\mathrm{pH}$ and biomarkers of tissue hypoxia at the stages of surgical treatment in the main group

\begin{tabular}{|c|c|c|c|c|}
\hline \multicolumn{1}{|c|}{ Stages } & $\mathrm{SpO}_{2}, \%$ & $\mathrm{pH}$ & $\begin{array}{c}\mathrm{BLL}, \\
\mathrm{mmol} / \mathrm{L}\end{array}$ & $\begin{array}{c}\mathrm{LDH}, \\
\mathrm{U} / \mathrm{L}\end{array}$ \\
\hline Before surgery & $97.63 \pm 0.58$ & $7.39 \pm 0.002$ & $1.19 \pm 0.04$ & $167.41 \pm 5.87$ \\
\hline $\begin{array}{l}30 \text { minutes after } \\
\text { PP creation }\end{array}$ & $96.14 \pm 1.21$ & $7.4 \pm 0.001$ & $1.39 \pm 0.06$ & $161.73 \pm 5.40$ \\
\hline $\begin{array}{l}\text { After } \\
\text { desufflation }\end{array}$ & $98.21 \pm 0.91$ & $7.4 \pm 0.001$ & $1.59 \pm 0.05$ & $153.34 \pm 5.42$ \\
\hline$P$ & $>0.05$ & $>0.05$ & $<0.05$ & $<0.05$ \\
\hline \multicolumn{1}{|c|}{$P$} & & & \multicolumn{2}{|c|}{} \\
\hline
\end{tabular}

When analyzing the levels of blood biomarkers of tissue hypoxia (Table 4) in patients of MG, moderate changes were established when creating intense pneumoperitoneum. blood lactate level in all measured time intervals corresponded to the physiological norm, while a moderate increase was observed after performing laparoscopic cholecystectomy, relative to the initial ones $(1.59 \pm 0.05 \mathrm{mmol} / \mathrm{L}$ versus $1.19 \pm 0.04 \mathrm{mmol} / \mathrm{L})$. Fluctuations in lactate dehydrogenase levels at the same time had the opposite character. There was a moderate decrease in the lactate dehydrogenase level after performing laparoscopic cholecystectomy, relative to the initial data $(153.45 \pm 5.42 \mathrm{U} / \mathrm{L}$ versus $167.41 \pm 5.87 \mathrm{U} / \mathrm{L})$.

\section{Discussion}

To identify the advantages and possible disadvantages of the proposed methods of pharmacological correction of hypoxic changes during intense pneumoperitoneum, perioperative results were compared in patients of the main group and comparison groups. The analysis of cardiovascular complications associated with pneumoperitoneum during laparoscopic cholecystectomy in patients of both groups revealed significant differences. In the comparison group, cardiovascular complications were observed in $15(25.86 \%)$ patients. Heart rhythm abnormalities were diagnosed in 2 $(3.45 \%)$ cases, asystole in $1(1.72 \%)$ patient, a drop in MBP by more than $20 \%$ in the intraoperative period of the initial level in 2(3.45\%) patients, and tachycardia more $120 \mathrm{bpm}$ in $3(5.17 \%)$ cases. In one patient, an episode of atrial fibrillation in the early postoperative period was recorded with successful medical cardioversion. One patient during ECG monitoring within 48 hours after surgery showed signs of subendocardial ischemia; one patient showed signs of subepicardial ischemia of the anterior wall of the left ventricle; and 2(3.45\%) patients showed signs of transmural ischemia of the posterior wall of the left ventricle. Two patients with ischemic heart disease had an attack of angina pectoris with ST segment depression. In all cases, effective relief of ischemia was achieved by the use of nitrates.

In the main group, cardiovascular complication were observed in $3(6.82 \%)$ patients. So, in one $(1.72 \%)$ patient during ECG monitoring, signs of transmural ischemia of the posterior wall of the left ventricle were recorded, which were stopped by administering nitrates and cardiometabolic drugs. Two $(3.45 \%)$ patients in the early postoperative period developed a hypertensive crisis against the background of hypertension. The use of oral antihypertensive drugs provided a decrease in blood pressure to target values.

Such significant differences in the number of cardiovascular complications in patients of the studied groups are associated with adequate pharmacological correction of hypoperfusion, and tissue hypoxia resulting from it, against the background of intense pneumoperitoneum during laparoscopic cholecystectomy. The fact that reperfusion pneumoperitoneums occur in the early postoperative period (1-2 days of the postoperative period) indicates that this period creates the conditions and prerequisites for their occurrence. This is confirmed by data on monitoring the level of lactate.

The technology of intense pneumoperitoneum in cases of laparoscopic cholecystectomy in patients with acute calculous cholecystitis has a significant stressful and traumatic effect on the body due to variable changes in hemodynamic parameters (heart rate, systolic blood pressure, diastolic blood pressure, mean blood pressure), blood $\mathrm{pH}$ and $\mathrm{SpO}_{2}$. These changes lead to ischemic and reperfusion changes, which create conditions and prerequisites for the development of ischemic cardiovascular complications in the early postoperative period. The proposed pathogenetically substantiated method of drug correction of hypoxic changes during intense pneumoperitoneum makes it possible to level out ischemic and reperfusion changes that occur during 
laparoscopic cholecystectomy in patients with acute calculous cholecystitis, having a protective effect on blood lactate level in patients of the main group, statistically significantly $(P<0.05)$ reducing its level after desufflation. The use of the proposed method for the medical correction of hypoxic changes in cases of intense pneumoperitoneum significantly $(P<0.05)$ reduces the number of cardiovascular complications provoked by ischemic disorders on the background of pneumoperitoneum by 3.79 times.

\section{Competing Interests}

The authors declare that they have no competing interests.

\section{References}

1. Slonetskyi B, Tutchenko M, Verbitskyi I, Roschin G. Role of minimally invasive technologies in treatment of acute surgical diseases of abdominal cavity. Emergency medicine. 2018;7(1):19-25.

2. Natroshvili IG, Prudkov MI. How active should be surgical tactic in treatment of acute cholecystitis? RUDN Journal of Medicine. 2019;23(2):156-167. doi. 10.22363/2313-02452019-23-2-156-167. [Article in Russian].

3. Goh JC, Tan JK, Lim JW, Shridhar IG, Madhavan K, Kow AW. Laparoscopic cholecystectomy for acute cholecystitis: an analysis of early versus delayed cholecystectomy and predictive factors for conversion. Minerva Chir. 2017;72(6):455-463. doi.10.23736/S0026-4733.17.07412-0.

4. Brooks KR, Scarborough JE, Vaslef SN, Shapiro ML. No need to wait: an analysis of the timing of cholecystectomy during admission for acute cholecystitis using the American College of Surgeons National Surgical Quality Improvement Program database. J Trauma Acute Care Surg. 2013;74(1):16773; 173-4. doi. 10.1097/TA.0b013e3182788b71.

5. de Mestral C, Hoch JS, Laupacis A, Wijeysundera HC, Rotstein OD, Alali AS, Nathens AB. Early Cholecystectomy for Acute Cholecystitis Offers the Best Outcomes at the Least Cost: A Model-Based Cost-Utility Analysis. J Am Coll Surg. 2016 Feb;222(2):185-94. doi: 10.1016/j. jamcollsurg.2015.10.015.
6. Leschenko IG, Kachanov VA, Polovkov AS, Dyakov GV, Sergeychev AK, Katasonov MV, et al. The question of tactics and elderly patients with acute senile destructive cholecystitis. Tol'yattinskij medicinskij konsilium. 2014;(1-2):22-30. [Article in Russian].

7. Kossaeva SB, Aimagambetov MZh. [Modern view on the diagnosis and treatment of acute cholecystitis in persons Over 60 years of age. A literature review]. Science \& Healthcare. 2018; 20(2);148-167. [Article in Russian].

8. Okamoto K, Suzuki K, Takada T, Strasberg SM, Asbun HJ, Endo I, et al. Tokyo Guidelines 2018: flowchart for the management of acute cholecystitis. J Hepatobiliary Pancreat Sci. 2018;25(1):55-72. doi: 10.1002/jhbp.516.

9. Ozkardeş AB, Tokaç M, Dumlu EG, Bozkurt B, Ciftçi AB, Yetişir F, Kiliç M. Early Versus Delayed Laparoscopic Cholecystectomy for Acute Cholecystitis: A Prospective, Randomized Study. Int Surg. 2014;99(1):56-61. doi: 10.9738/ INTSURG-D-13-00068.1

10. Gul R, Dar RA, Sheikh RA, Salroo NA, Matoo AR, Wani SH. Comparison of Early and Delayed Laparoscopic Cholecystectomy for Acute Cholecystitis: Experience from A Single Center. N Am J Med Sci. 2013;5(7):414-418. doi: 10.4103/1947-2714.115783

11. Saber A, Hokkam EN. Operative outcome and patient satisfaction in early and delayed laparoscopic cholecystectomy for acute cholecystitis. Minim Invasive Surg. 2014:2014:162643. doi: 10.1155/2014/162643.

12. Shlyk IV, Zakharenko AA, Panafidina VA, Trushin AA, Ten OA. [Impact of intra-operative intra-abdominal hypertension on the course of post-operative period in the patients undergoing surgery for colorectal cancer]. Messenger of Anesthesiology and Resuscitation. 2017;14(6):28-36. doi:10.21292/2078-5658-2017-14-6-28-36. [Article in Russian].

13. Velichko EA, Nekrasov AY, Sergeev AV. [The role laparoscopic without gas in treatment patients with acute cholecystitis with high anesthesiology-operations risk]. Klinicheskaya gerontologiya. 2015;(11-12):7-13. [Article in Russian].

14. Hryvenko SH, Golomidov OM, inventors; Hryvenko SH, Golomidov OM, assignees. Method for the prevention and treatment of hypoxic changes in carboperitoneum. Ukraine patent UA 119602. 2017 September 25. [in Ukrainian]. 